\title{
Nesting Ecology of a Small Montane Population of the Nigerian/Cameroon Chimpanzee (Pan troglodytes ellioti) in Nigeria
}

\author{
Paul Dutton $^{\mathrm{a}}$ Elena Moltchanova ${ }^{\mathrm{b}}$ Hazel Chapman $^{\mathrm{a}}$ \\ ${ }^{a}$ School of Biological Sciences and bepartment of Mathematics and Statistics, \\ University of Canterbury, Christchurch, New Zealand
}

\section{Keywords}

Chimpanzee $\cdot$ Nesting $\cdot$ Nigeria $\cdot$ Pan troglodytes ellioti $\cdot$ Trails $\cdot$ Site selection

\begin{abstract}
Understanding nest site choice by chimpanzees has implications for ecology, anthropology, and in the collection of census data, yet it remains controversial. Here we provide the first information on environmental factors affecting nest site choice in a montane population of the rare and relatively understudied Nigerian/Cameroon chimpanzee (Pan troglodytes ellioti) in Ngel Nyaki Forest Reserve, Nigeria. The forest is small, isolated, and visited by researchers, community members, and hunters. We also tested the hypothesis that people (researchers) walking along forest trails collecting data on a regular basis since 2005 will have changed nesting behaviour in the vicinity of the trails. Along the trails searched for nests, the chimpanzees used a subset of 35 (28.5\%) of all available tree species. The top 5 nest tree species represented $16 \%$ of all non-nest tree species. The nest trees were on steeper than average slopes and the trees themselves were shorter and had a smaller DBH (diameter at breast height) than trees without nests. We found no evidence to suggest a change in nesting behaviour along trails compared with off trails; however, the average nest height today is considerably higher than it was in 2004, which may indicate a change in behaviour across the whole forest.
\end{abstract}

(c) 2017 S. Karger AG, Basel

\section{Introduction}

All great ape species make night nests, sleeping platforms made in the branches of trees or in some cases on the ground [Fruth and Hohmann, 1996]. Nests in trees combine plant materials into 3 nest components: a frame, a central mattress and a

\begin{tabular}{ll}
\hline KARGER & ○ 2017 S. Karger AG, Basel \\
E-Mail karger@karger.com & $0015-5713 / 17 / 0876-0361 \$ 39.50 / 0$ \\
www.karger.com/fpr &
\end{tabular}

Paul Dutton

University of Canterbury

Private Bag 4800

Christchurch 8140 (New Zealand)

E-Mail duttonpe@ hotmail.com 
lining made of additional leaves and twigs [McGrew, 1992]. These 3 components together provide more efficient thermoregulation as compared to ground nests, aid comfortable sleeping postures and provide a more relaxed sleep because there is less need to be vigilant [Fowler, 2006]. Great apes are very selective when choosing their night nest site, yet what determines their choice remains controversial despite numerous studies over many years [reviewed in Hernandez-Aguilar et al., 2013].

Chimpanzees (Pan troglodytes) spend approximately half of their lives within the confines of a "nesting site." Weaned individuals most commonly construct a new nest, although sometimes an old nest is refurbished and reused, so that on average an individual constructs 19,000 nests during its lifetime [Fruth and Hohmann, 1994]. Nest sites in particular locations are often reused well after the nests themselves have decayed [Stewart et al., 2011], which suggests that chimpanzees prefer certain sites over others. This fact has led to the investigation of which environmental [Koops et al., 2012], ecological [Baldwin et al., 1981; Anderson et al., 1983; Brownlow et al., 2001; Samson and Hunt, 2014] and/or behavioural [McGrew, 1992; Reynolds, 2005; Stewart and Pruetz, 2013] drivers are the strongest for nesting site choice.

Human disturbance can be a highly influential factor in nest site selection, particularly in areas where human population pressure and hunting is high. For example, in both the northern Democratic Republic of Congo [Hicks, 2010] and Cameroon [Last and Muh, 2013] a higher prevalence of ground nesting was associated with lower human density. Moreover, arboreal nests may be built higher up in trees in response to human presence [Plumtree and Reynolds, 1997; Last and Muh, 2013; Stewart and Pruetz, 2013]. In Guinea-Bissau, chimpanzee nests were exclusively arboreal and were more common away from proxies of human disturbance such as settlements and roads, suggesting a negative influence of human disturbance on chimpanzee distribution [Carvalho, 2015]. Chimpanzee density estimates and encounter rates per kilometre in Southeast Cameroon were lower on established transects than on new ones where there was more anthropogenic activity [Tagg and Willie, 2013]. Likewise, in the Central African Republic, Hicks et al. [2009] found a strong negative relationship between hunting pressure and chimpanzee encounters. Their encounter rate for ape nests declined as they moved from intact forest into transected forest and then dropped nearly to zero in the logged areas of Ngotto Forest. These examples suggest that the use of repeated transect surveying for monitoring chimpanzee populations and the establishment of permanent trails throughout the forest may influence chimpanzee nesting behaviour.

The choice of nest site in the relatively understudied Nigerian-Cameroon chimpanzee, Pan troglodytes ellioti, has so far only been investigated in one large, unhabituated, relatively undisturbed lowland ( $\pm 300 \mathrm{~m}$ elevation) population in Gashaka Gumti National Park (GGNP) [Fowler, 2006]. GGNP provides a haven for primates in this part of Nigeria, due more to its remoteness and large geographic area than to adequate protection [Adanu et al., 2011]. In contrast, Ngel Nyaki Forest Reserve (NNFR), the focus of this study, has a small, unhabituated, isolated and poorly protected montane population of P. t. ellioti [Beck and Chapman, 2008; Dutton and Chapman, 2015]. These chimpanzees live approximately $50 \mathrm{~km}$ away from the GGNP population and recently became isolated, possibly due to the paving of the road running between NNFR and GGNP and the steep increase in the human population [Knight, 2014]. 
During our study of chimpanzee nest site choice in NNFR we aimed to: (i) identify key ecological factors (such as tree species, slope, distance to water, and distance to edible fruit) associated with chimpanzee nest sites, and (ii) determine whether researchers walking along forest trails on a regular basis influence chimpanzee nesting decisions. Specifically we tested the hypotheses outlined as follows.

Chimpanzees would choose a small subset of available tree species in which to build nests and these trees would be positively associated with the proximity to fruit and water. That chimpanzees show preference for particular tree species has been reported in several previous studies [e.g. De Bournonville, 1967; Kano, 1983; Fruth and Hohmann, 1994], as has a preference for nesting near food and water [Baldwin et al., 1981; Anderson, 1984; Sept et al., 1992; Basabose and Yamagiwa, 2002].

Chimpanzees would avoid building nests along trails regularly walked by human researchers/field assistants as suggested by Plumptre and Reynolds [1997] and Tagg and Willie [2013], or, if nests were built in trees along trails, they would be higher in the trees than are nests in equivalent trees away from trails. This would make sense in terms of the predator avoidance hypothesis [Pruetz, 2013]. Using similar reasoning, we hypothesised that nests in trees along trails should be higher in trees during this study than they were in 2004 when they were measured by Beck [2006], before the regular presence of researchers in the forest.

\section{Methods}

Study Site

NNFR $\left(46 \mathrm{~km}^{2} ; 11^{\circ} 00^{\prime}-11^{\circ} 30^{\prime} \mathrm{N}, 6^{\circ} 30^{\prime}-7^{\circ} 15^{\prime} \mathrm{E}\right)$ is located towards the western escarpment of the Mambilla Plateau in Taraba State, Nigeria (Fig. 1). The forested area of the reserve is approximately $7.5 \mathrm{~km}^{2}$ comprising submontane forest restricted to steep slopes between 1,500 and $1,600 \mathrm{~m}$ above sea level [Chapman and Chapman, 2001]. Outside of the reserve, forest cover is sparse and restricted to small degraded riparian fragments. Mambilla Plateau comprises rolling hills covered in heavily overgrazed Sporobolus grassland. The plateau is home to indigenous Mambilla farmers and Fulani cattle rearers. Grass is burnt annually to stimulate grass growth and fire frequently penetrates the forest; hunting is also common. The Mambilla Plateau chimpanzees are mainly confined to 2 relatively large forest fragments within NNFR, Ngel Nyaki forest and Kurmin Danko [Chapman et al., 2004]. The total weaned population size of P. t. ellioti in the reserve has been estimated at 16 individuals with a population density $>2.1 / \mathrm{km}^{2}$ [Dutton, 2012]. Other primates are well represented within these forest fragments; in addition to chimpanzees, there are putty-nosed monkeys (Cercopithecus nictitans; Linnaeus, 1766), black and white colobus (Colobus guereza occidentalis; de Rochebrune, 1887), mona monkeys (Cercopithecus mona; Schreber, 1775), tantalus monkeys (Chlorocebus tantalus; Ogilby, 1841), olive baboons (Papio anubis; Lesson, 1827), patas monkeys (Erythrocebus patas; Schreber, 1774) and Demidoff's galago (Galagoides demidovii; Fischer, 1806). Other mammals recorded in the Reserve include African buffalo (Syncerus caffer; Sparrman, 1779), red river hog (Potamochoerus porcus; Linnaeus, 1758), bushbuck (Tragelaphus scriptus; Pallas, 1766), duiker (Cephalophus silvicultor; Afzelius, 1815), civet (Civettictis civetta; Schreber, 1776) and African brush-tailed porcupine (Atherurus africanus; Gray, 1842). Chimpanzee predators once included leopard (Panthera pardus; Linnaeus, 1758) [Boesch and Boesch, 1989; Hayward et al. 2006] and possibly lion (Panthera leo; Linnaeus, 1758), African wild dog (Lycaon pictusand) and hyaena (Crocuta crocuta) [Stewart and Pruetz, 2013]. However, over the past 30 years elephant, buffalo and all chimpanzee predators have become locally extinct [Chapman et al., 2004], leaving humans as the only predators of the chimpanzees living in NNFR. Since 2005, the Nigerian Montane Forest Project (NMFP) has operated with its field station within the reserve boundary. As a result, over $17 \mathrm{~km}$ of forest trails have been laid out approximately $500 \mathrm{~m}$ apart. These trails have not been cut, so as to reduce their impact to a minimum, 

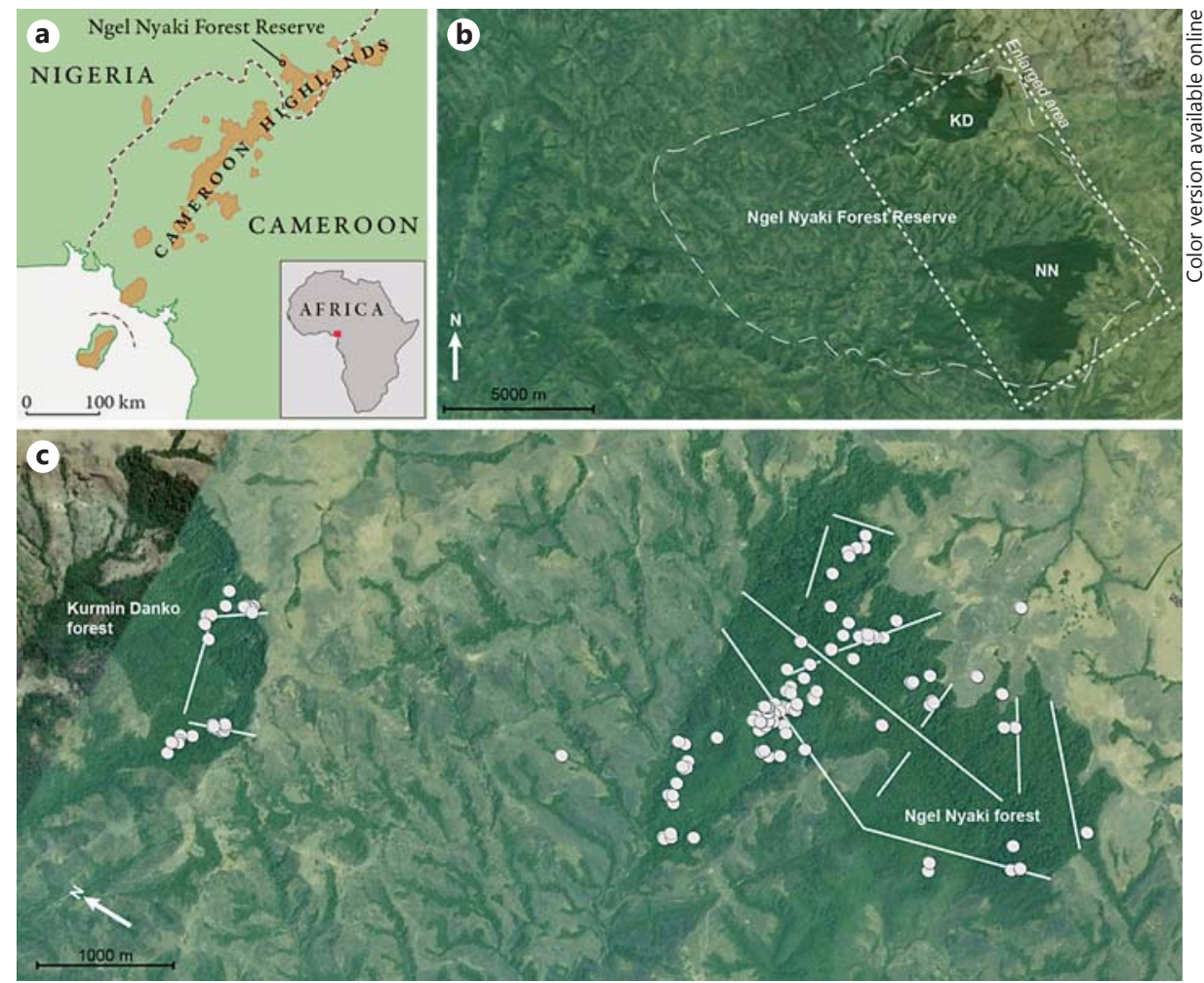

Fig. 1. a The location of NNFR in Nigeria. b The reserve boundary. KD, Kurmin Danko; NN, Ngel Nyaki. c Transects used for the collection of chimpanzee nest data (white lines) and nesting data waypoints (white dots).

but trees $2 \mathrm{~m}$ on either side of the transect "line" have been labelled and are visited for phenology observations on a monthly or fortnightly basis. Through this use, paths have evolved and trails are walked by visitors and researchers on a regular basis. While this human presence has reduced hunting in the forest, as evidenced by the reduction in snares and other traps collected in the areas where researchers work [Chapman, pers. commun.], it is possible that the regular human presence is changing chimpanzee behaviour. As NNFR is a small, relatively isolated forest reserve with little movement of chimpanzees in or out of it [Knight, 2014], the chimpanzees have to accommodate people; without doubt human presence within NNFR is higher now than it was prior to 2005, although there are fewer hunters. Investigations of how chimpanzees adapt to this increase is urgent both in terms of managing research and, potentially, tourism. As ecotourism becomes increasingly popular [Fennell, 2012] reserves such as NNFR are becoming increasingly attractive destinations.

\section{Locating Nests}

Between October 2009 and April 2011, we utilized $10.7 \mathrm{~km}$ of previously established trails (made in 2006) and $6.4 \mathrm{~km}$ of newly established trails. The $17.1 \mathrm{~km}$ of trail ranged in length from 1.1 to $4.2 \mathrm{~km}$, established along "straight" lines (500 m apart) and did not follow any biological features. The nests we discovered along trails are here referred to as "ON" and nests $>100 \mathrm{~m}$ away from trails we refer to as "OFF". The latter we discovered opportunistically, often as a result of following chimpanzee vocalisations. 
In order to locate nests we walked all of the trails 17 times at 12-day intervals. Two to 3 people walked at an even pace $(<1 \mathrm{~km}$ per hour) and stopped frequently to look in all directions for nests. Initially, we walked the trails in both directions, but after 3 months with no further detections on the return visit, we abandoned the return visit. We recorded all visible nests, and measured the exact perpendicular distance from the closest point on the trail to directly below the nest [Plumptre and Reynolds, 1997]. We marked every tree containing a nest with a numbered tag [Matthews and Matthews, 2004], which eliminated the possibility of us counting nests twice and increased the chances of us recognizing nests when they were in an advanced state of decay. We distinguished day nests from night nests by the simple, poorly insulated structure of the former [Johnson et al., 2005; Fowler, 2006]. We only collected data when the nests were new and had obviously been built by the chimpanzees after the previous survey. Evidence that nests were new came from observing chimpanzees close to nest sites, the presence of fresh leaves woven into the nests, nests retaining their insulated design, newly broken branches (sometimes exhibiting resin), fresh feeding remains, faecal samples or combinations of the above. This sampling protocol was approved by the University of Canterbury Animal Ethics Committee, Approval No. 2009/26R and the research was in compliance with the laws governing animal research in Nigeria.

\section{Measuring Variables}

In order to estimate how often each trail was walked, we combined the frequency that trails were walked for locating nests with the frequency of their use by other researchers in the forest and found that each trail was walked on average every 4.6 days. While we were aware that hunters, patrollers and locals walk the trails as well, this additional usage became too difficult to measure accurately.

In order to investigate whether chimpanzee nesting behaviour was influenced by transects we compared the following 7 factors: tree height, tree DBH (diameter at breast height), slope, distance to edible fruit, distance to water, tree species and species of closest edible fruit from 339 non-nesting trees (NNT) with chimpanzee nesting trees. Our NNTs were from 11 random $100 \mathrm{~m}$ sections of forest. For a sample tree to be measured it was required to have a DBH of $>10 \mathrm{~cm}$ and to be growing within $2.5 \mathrm{~m}$ on either side of the $100 \mathrm{~m}$ strip.

In order to test hypotheses 1 , that chimpanzees would choose a small subset of available tree species in which to build nests and these trees would be positively associated with proximity to fruit and water, we recorded variables at each nest site following the methods used by Fowler [2006]. We first identified the tree species in which the nest was built and then the species of closest edible fruit to the nest. To locate the closest fruit tree we walked round the perimeter of the nest tree in ever increasing circles until a fruiting tree was found. We mainly identified trees using local knowledge (the NMFP field assistants are well educated in tree identification), but when necessary we referred to tree taxonomic guides [Keay, 1990; Hawthorne and Jongkind, 2006], the West African Plants Facebook group and/or a checklist of plants from NNFR at http://www.afromontane.canterbury.ac.nz/checklist.shtml. It was not always possible to identify or distinguish between all species of any particular genus. "Unidentified" species included 7 species ( 25 individuals) of nesting trees and 20 species ( 29 individuals) of NNT. Ficus spp. included 3 species ( 5 individuals) of nesting trees and 7 species (56 individuals) of NNT ( 5 of which we have since identified as: F. chlamydocarpa, F. lutea, F. polita, F. sansibarica and F. sur).

To determine whether the season - rainy versus dry - influenced the choice of nest height, we measured 3 climatic variables - temperature, precipitation and humidity. These measures were recorded from a Campbell automated weather station located at the NMFP field station.

We measured the tree and habitat characteristics including nest height, tree height and angle of slope using a clinometer (SUUNTO PM5/360PC). The habitat characteristics "distance to edible fruit" and "distance to water" were measured using a tape measure if either occurred within a $100 \mathrm{~m}$ radius of the nest. We searched for fruit trees and water sources within the vicinity of nest trees following the methods of Fowler [2006]. We measured the distance to edible fruit by standing directly under the nest and using a tape measure to measure the distance to the area on the ground directly under the nearest ripe fruit we knew to be consumed by chimpanzees. We 
measured the distance to water using a standard 50-m tape measure and standing under the nest while another person ran the tape to the nearest water source. The tree characteristic DBH of each nesting tree was measured at $1.4 \mathrm{~m}$ above the forest floor [Sun et al., 1996], when the tree was on a slope, we chose the uphill side of the tree for the measurement. For trees with buttresses, we measured above the buttress, and when a tree bifurcated below the standard DBH we measured both stems and combined their diameters.

To test hypothesis 2 , i.e. that the presence of researchers routinely walking along trails for data collection was dissuading chimpanzees from nesting in these areas, or making them nest higher up in trees, we measured and compared the variables (tree height, tree DBH, slope, distance to edible fruit, distance to water, tree species and closest edible fruit species) between nests discovered on trails with nests discovered off trails (over $100 \mathrm{~m}$ away).

\section{Data Analysis}

Nest Variable Associations

We used a general linear model (GLM) to examine the influence of the variables: tree species, tree height, tree $\mathrm{DBH}$, slope, distance to edible fruit, distance to water, temperature, precipitation and humidity on nest height. Secondly, in an attempt to explain nest height further, we used a fitted Tobit model to estimate any correlation between variables when there was right censoring in the dependent variable (i.e. nest height was limited by tree height) and included slope and DBH, precipitation, relative humidity and temperature as variables. In order to conduct this analysis, we sourced additional data from the 1,053 tagged trees used for phenology research along all previously established trails. Only trees with a DBH $\geq 10 \mathrm{~cm}$ and growing within $2.0 \mathrm{~m}$ either side of a trail were measured.

To identify the selection of particular nesting variables by chimpanzees, we compared the NNT $(n=339)$ variables (tree height, tree DBH, slope, distance to edible fruit, distance to water, tree species and closest edible fruit species) to nesting tree variables. We used the Welch 2-sample $t$ test to identify differences between the means of nesting tree and NNT heights and DBHs because they were not normally distributed when using a Shapiro-Wilk normality test.

Influence of Trails on Nest Site

As the 2 samples (i.e. "ON" trails and "OFF" trails) were from the same population and because data followed a normal distribution using a Shapiro-Wilk normality test, we used paired $t$ tests to analyse the nest height, tree height and slope data. Paired $t$ tests were also used to determine if the presence of trails influenced the measured nesting variables (tree height, tree $\mathrm{DBH}$, slope, distance to edible fruit, distance to water, tree species and closest edible fruit species). We classed statistical calculations as significant at $p<0.05$. All analyses were conducted using R software [R Development Core Team, 2011].

\section{Results}

During this study we located 311 night nests, 139 nests along previously established trails and 172 nests at least $100 \mathrm{~m}$ away from trails.

\section{Nest Tree Species Preference}

Chimpanzees used 35 (28.5\%) of the 123 tree species recorded ON trails for nesting. The top 5 identified nesting tree species, Anthonotha noldeae, Macaranga monandra, Strombosia scheffleri, Trichilia welwitschii and Isolona deightonii, represented $52.9 \%$ of all nesting tree species and only $16.8 \%$ of NNT species (Fig. 2), suggesting a preference. In contrast, the top 5 NNT species, Anthonotha noldeae, Ficus spp., Bombax sp., Pouteria altissima and Strombosia scheffleri, represented $48.4 \%$ of all NNT species but only $28.7 \%$ of nesting tree species. 


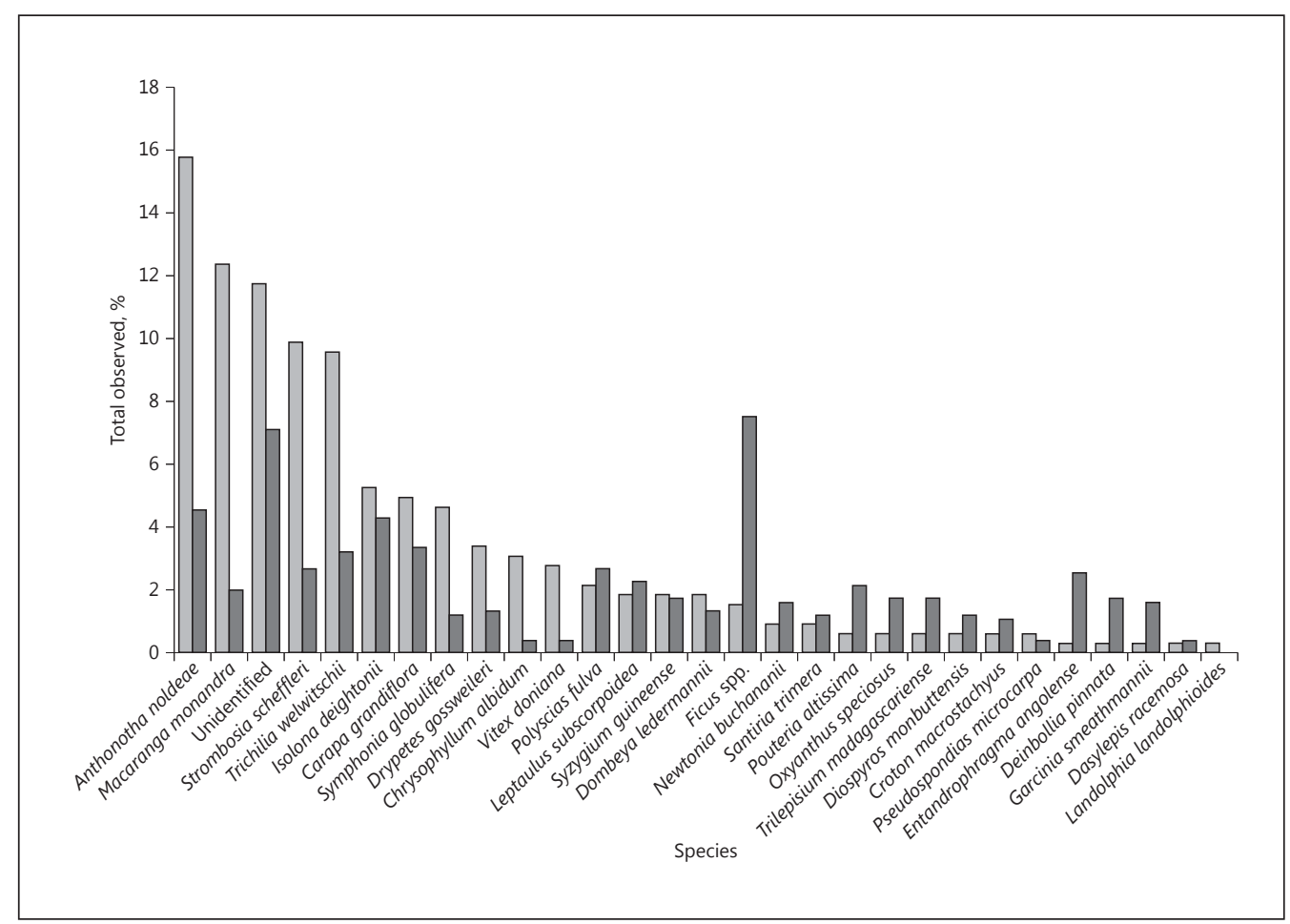

Fig. 2. Comparative percentages of tree species present along transects (light grey) and those used in nest construction (dark grey) throughout the forest. The 5 most frequently used species were used for over $50 \%$ of all nest construction.

\section{Descriptive Nesting Variables}

The mean nest height was $20.5 \mathrm{~m}(n=311$; median $=20$; $\mathrm{SD}=7.18)$ with a maximum height of $37.7 \mathrm{~m}$ and a minimum height of $4.0 \mathrm{~m}$. Fifty per cent of all nests were between 13 and $20 \mathrm{~m}$ in height and nesting tree DBHs ranged from 7.8 to $264 \mathrm{~cm}$ $(n=311 ;$ mean $=37.6 \mathrm{~cm}$; median $=32.7 ; \mathrm{SD}=23.0)$. The mean nesting tree height was $25.3 \mathrm{~m}(n=311$; median $=24 ; \mathrm{SD}=7.75)$ with a range from $8.0 \mathrm{~m}$ to $39.8 \mathrm{~m}$. The mean angle of slope where nests were found was $29.7^{\circ}(n=311$; median $=30.5$; $\mathrm{SD}=$ 10.36; range $=0-54)$ and the chimpanzees nested $(n=233)$ close to either Ficus spp. (89.6\%) or Landolphia landophioides (52.7\%) fruits. In total, $49.7 \%$ of all nests were within $90 \mathrm{~m}$ of water $(n=163$; mean 36.2; SD 30.2; range $0-90)$.

\section{Nest Variable Associations}

Tree height was the only measured variable associated with nest height $(t=2.923$, $p<0.005, R^{2}=0.9068$; Fig. 3; Table 1), with nest height increasing with tree height. We found nest height was always within $8.5 \mathrm{~m}$ of tree height for all tree species.

We used a fitted Tobit model (with tree height restriction) to test the other variables associated with nest height. The significant variables $\left(\chi^{2}=73.95, p<0.001\right)$ were DBH ( $z=8.297, p<0.001$; nests were made higher as DBH increased), temperature 


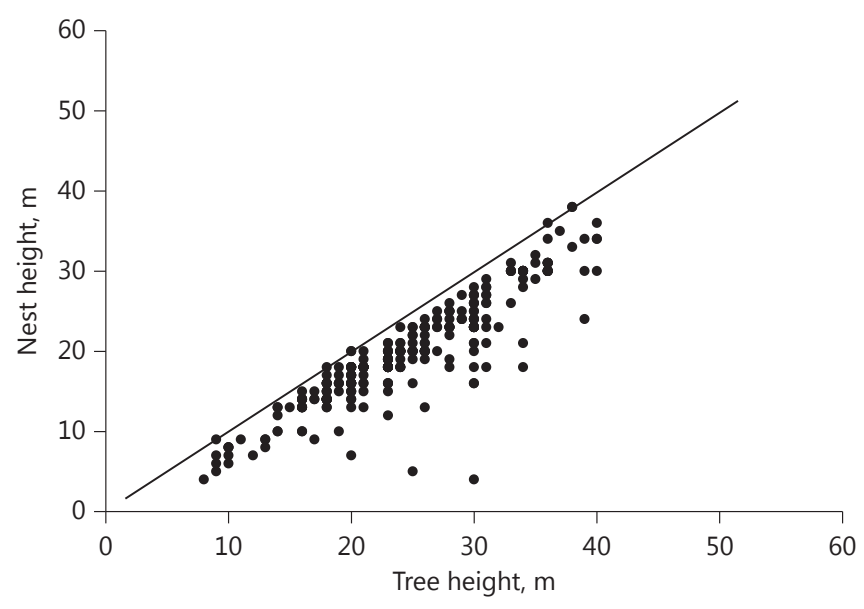

Fig. 3. Results of a linear model showing a relationship between nest height $(\mathrm{m})$ and tree height $(\mathrm{m})$, showing that nest height is limited by tree height.

Table 1. Linear model of nest height showing the model estimate, standard error (SE), $t$ value and significance of the different variables

\begin{tabular}{lclrl}
\hline Variable & Estimate & SE & $t$ value & $\operatorname{Pr}(>|\mathrm{t}|)$ \\
\hline Slope $\left({ }^{\circ}\right)$ & -0.00178 & 0.00388 & -0.459 & 0.64692 \\
DBH $(\mathrm{cm})$ & -0.00337 & 0.0025 & -1.346 & 0.17962 \\
Temperature $\left({ }^{\circ} \mathrm{C}\right)$ & 0.00225 & 0.02479 & 0.091 & 0.92777 \\
Relative humidity $(\%)$ & 0.002586 & 0.00168 & 1.539 & 0.12526 \\
Precipitation $(\mathrm{mm})$ & -0.00029 & 0.00137 & -0.211 & 0.83279 \\
Tree height $(\mathrm{m})$ & 0.018365 & 0.00628 & 2.923 & 0.00383 \\
\hline
\end{tabular}

Tree height was the only significant variable.

( $z=3.367, p<0.001$; nests were made higher as temperature increased) and precipitation $(z=2.948, p<0.005$; nests were built lower in trees during the rainy season as precipitation increased; Table 2). When comparing nesting tree variables to NNT variables, nesting trees were significantly smaller than NNTs in both height (Fig. 4a) and DBH (Fig. 4b; Welch 2-sample $t$ test, $p<0.001$; Table 3).

\section{Influence of Trails on Nesting}

To assess whether the use of trails influences chimpanzee nesting patterns, we compared nesting data recorded ON trails $(n=139)$ with nesting data recorded OFF trails $(n=172)$. 


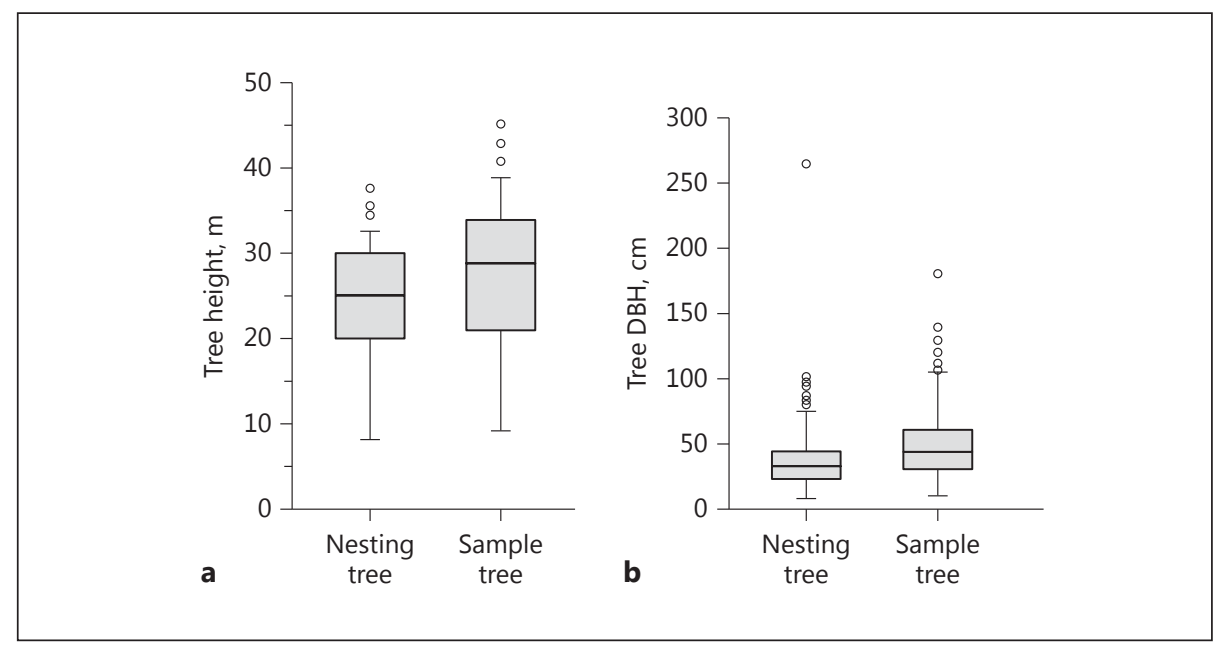

Fig. 4. Box plots of tree height (a) and DBH (b) of chimpanzee nesting trees and sample trees showing significant differences. Nesting trees were significantly smaller than sample trees in both height and DBH.

Table 2. Fitted Tobit model of nest height showing the model value, standard error (SE), $z$ value and significance of the different variables

\begin{tabular}{lllcr}
\hline Variable & Value & SE & $z$ & \multicolumn{1}{c}{$p$} \\
\hline Slope $\left({ }^{\circ}\right)$ & 0.0444 & 0.04 & 1.111 & 0.267 \\
DBH $(\mathrm{cm})$ & 0.1755 & 0.0212 & 8.297 & $<0.001$ \\
Temperature $\left({ }^{\circ} \mathrm{C}\right)$ & 0.8493 & 0.2522 & 3.367 & $<0.001$ \\
Relative humidity $(\%)$ & 0.0224 & 0.0175 & 1.28 & 0.201 \\
Precipitation $(\mathrm{mm})$ & -0.0413 & 0.014 & -2.948 & $<0.003$ \\
\hline
\end{tabular}

$\mathrm{DBH}$, temperature, and precipitation were significant variables.

Table 3. Welch 2-sample $t$ test for tree height and $\mathrm{DBH}$ of chimpanzee nesting trees and sample trees showing significant differences

\begin{tabular}{lccl}
\hline & Nesting trees & Sample trees & $p$ \\
\hline$n$ & 311 & 339 & \\
Tree height, m & $25.28(7.75)$ & $28.46(9.19)$ & $<0.001$ \\
DBH, cm & $37.59(22.99)$ & $51.35(26.06)$ & $<0.001$ \\
\hline
\end{tabular}

Nesting trees were significantly smaller than sample trees in both height and DBH. Mean with $\mathrm{SD}$ in parentheses. 
We found no significant differences in nest height $(t=0.9062, p=0.366)$ or tree height $(t=0.1496, p=0.881)$ ON versus OFF trails. However, there was a significant difference in tree diameter $(V=2,368.5, p<0.001)$, with nests $\mathrm{ON}$ trails occurring in smaller-diameter trees. Moreover, the distance to water was significantly different for nests $\mathrm{ON}$ versus OFF trails $(V=566.5, p<0.001)$, with nests on trails occurring further away from water. Likewise, the distance to fruit was significantly different $(V=$ $2,392.5, p<0.001)$ with nests ON trails being further away from fruit. In addition, slope was significantly different $(t=2.0072, p=0.046)$, with nests $\mathrm{ON}$ trails occurring on steeper slopes.

\section{Discussion}

Our results supported the hypothesis that chimpanzees choose a small subset of available tree species in which to build nests, and that these trees are positively associated with certain habitat variables. Only 35 out of $123(28.5 \%)$ tree species were used for nesting, and of these, 5 species accounted for $53 \%$ of all nesting tree species. Why certain tree species are sought after for nesting in is unclear and factors such as fruit production or gross morphological comparison of these preferred nest tree species does not immediately suggest why they are preferred. Of the top 5 nesting tree species used by chimpanzees in NNFR (Anthonotha macrophylla, Macaranga monandra, Strombosia scheffleri, Trichilia welwitschii and Isolona deightonii) only 1, I. deightonii is a preferred fruit species in their diet [Dutton and Chapman, 2015]. This is not unusual, most chimpanzees nest in non-fruiting trees but in close proximity to fruit trees [Fruth and Hohmann, 1994; Basabose and Yamagiwa, 2002], which is what we found. Over $89 \%$ of nests were close to Ficus species. Nesting away from fruiting trees may reduce disturbance from nocturnal fruit bats and early morning visits by scavengers of fruit lying on the ground, such as pigs and ungulates [Fowler, 2006]. Being the largest primates in NNFR, Ngel Nyaki chimpanzees have few serious competitors for fruit and consequently no need to nest in fruit trees [Basabose and Yamagiwa, 2002]. Biophysical properties may influence the choice of nest tree species; certain attributes such as branch stiffness and bending strength, or large leaf surface area arguably produce more comfortable nests. Chimpanzees in Toro-Semliki Wildlife Reserve in southwest Uganda preferentially chose Cynometra alexandri in which to build nests and, after biomechanical tests, Samson and Hunt [2014] concluded that this was because C. alexandri has a combination of branch and leaf characteristics which made a strong, safe and comfortable bed. Increased leafiness is another property that may be selected for to increase comfort and protection from detection by predators or disturbance by other foragers. Leafiness may also increase thermoregulation and reduce the likelihood of infection by pathogens [Fowler, 2006; Koops et al., 2012; Samson and Hunt, 2014]. While Fruth [1995] noted that bonobos in Lomako Forest, Democratic Republic of the Congo, preferentially chose trees with small- and medium-sized leaves in which to build nests, this is not the case for P. t. ellioti in NNFR. However, the top 5 identified nesting tree species did not obviously share any physical characteristics that might make them more preferred nest tree species than others and further investigation to understand nest tree choice at Ngel Nyaki is necessary. Alternatively, other factors, such as the presence of insects in trees, may influence nest tree choice. 
Many tree species in NNFR harbour bee or arboreal ant nests, and plagues of caterpillars are also common [Chapman, pers. commun.].

When comparing nesting tree variables to NNT variables, we found that nesting trees were significantly smaller than sample trees - they were shorter and narrower. That chimpanzees in NNFR select smaller than average trees in which to construct nests was unexpected and in contrast to the findings of Fowler [2006] in nearby GGNP, where he found that nesting trees, on average, were taller and had a greater DBH than non-nesting ones. However, that study was in a very different forest type; the Kwano study area comprised both savannah and lower altitude forest compared with NNFR (580 m above sea level compared with 1,600 m above sea level, respectively). Moreover, the Kwano chimpanzees sometimes used small savannah tree species in which to nest.

At NNFR, chimpanzees always nest within the forest; no nests were ever encountered in the savannah [Beck and Chapman, 2008; Dutton, 2012]. This suggests that Ngel Nyaki chimpanzees seek out safety in the forest, perhaps historically as protection from non-human predators [Stewart and Pruetz, 2013], or more recently to avoid hunters [Hicks, 2010]. This suggests that within NNFR, chimpanzees are wary of predators due to either historical or current threats, or most likely a combination of both. Nest height has been found to increase in response to predation [Rayadin and Saitoh, 2009], which implies that choosing to build nests in smaller than average trees, which are theoretically more accessible to all predators, is a trade-off between escape from predators by nesting in large trees, the advantages of nesting on steep slopes to avoid disturbance and see who is coming, and other factors such as quality of sleep.

Ngel Nyaki chimpanzees prefer to nest on steeper slopes, a common finding for chimpanzees elsewhere [e.g. Baldwin, 1979; Fowler, 2006; Furuichi and Hashimoto, 2004; Hakizimana et al., 2015; Hernandez-Aguilar, 2009]. Abwe and Morgan [2008] suggest that this behaviour in P. t. ellioti in Ebo forest, Cameroon, is a response to night hunting by humans. When compared to smaller trees on steeper slopes, tall, large trees are less common and less available in groups [Chapman and Chapman, 2001]. Chimpanzees like nesting in groups and being close together is important for social and security reasons [Anderson, 1998]. Other factors may be relevant as well. Building nests on steep, overhanging slopes may reduce disturbance by nocturnal foragers [Fowler, 2006], older trees with higher DBH may have more old and dead branches that are unsuitable for safe nest sites or provide suitable habitat for snakes. Their crowns may be more likely to be contaminated with parasitic plants such a strangling Ficus species. Old, tall trees may also be less stable during the extreme wind/rain storms that affect NNFR during early rains every year (NMFP weather data). In addition, the topography of NNFR is such that steep slopes are usually relatively close to water.

We found little evidence from the parameters we measured to suggest that chimpanzee nesting behaviour is changing in response to the presence of people along the trails. Our hypothesis that the chimpanzees would nest higher in trees in response to more human disturbance was not supported; we found no significant difference between nest height or nesting tree height ON trails with those OFF trails. The significant differences in nesting behaviour we did find between nests ON and OFF trails do not obviously indicate avoidance of researchers walking along the trails. If hunters use the trails then it could be argued that it is an anti-predator response if hunters avoid the steep slopes of the trails and spend more time using flat trails. However, we 
have no reason to believe that hunters do use the trails as we very rarely found evidence of snares along them. As discussed previously, the fact that nests ON trails are in smaller trees than those OFF trails may simply reflect topography - smaller trees are more common on steep slopes [Chapman and Chapman, 2001]. Moreover, that nest trees ON trails were further away from water and fruit does not appear to be adaptive.

The only suggestion that increased human activity in the forest may be changing nesting behaviour comes from comparing the nest heights reported by Beck [2006] for the same NNFR chimpanzee population. Beck [2006] found that, on average, in 2004 chimpanzees were nesting at $12.8 \mathrm{~m}$, with a maximum height of $30.2 \mathrm{~m}$. This average is $7.7 \mathrm{~m}$ lower than this study. While this discrepancy could reflect interannual/seasonal variation, in GGNP Fowler [2006] did not find a significant variation in nest height from month to month, and we suggest that the observed large height increase since 2004 may indicate that the chimpanzees are now nesting higher in response to the increased presence of researchers in the forest since 2006. Such a behavioural shift has been reported in response to the habituation of chimpanzees in Fongoli forest, Senegal [Stewart, 2011].

\section{Future Work}

In this first ever study of nesting behaviour in a small, montane population of P. t. ellioti we have demonstrated distinct preferences for certain tree species and for nesting on steep slopes, which may explain the unusual choice of smaller than average trees. The difference in mean nest height between 2004 [Beck, 2006] and 20092011(this study) is the only indication we found that the presence of researchers in the forest may be affecting chimpanzee behaviour. Future research is needed to explain the choice of the tree species; biomechanical studies following the ideas in Samson and Hunt [2014] would be appropriate. More evidence for or against a correlation between slope and tree size would be useful. Data collected during the first census of the new Smithsonian Centre for Tropical Forest Science (CTFS-ForestGEO plot) at Ngel Nyaki (http://www.ctfs.si.edu/site/Ngel+Nyaki) will be used to answer this question. The finding that humans are not affecting nesting behaviour should be better tested and this could be done by surveying all nests in the forest on a grid basis and comparing nest densities on and off trails. In order to untangle the effects of altitude and forest type from chimpanzee culture and anthropogenic disturbance, it would be useful to carry out a comparative analysis between the montane populations of P. t. ellioti in NNFR and GGNP.

\section{Acknowledgments}

Thanks to Taraba State Forestry for logistical support and Nigerian Montane Forest Project for field facilities and field assistance, especially to Alfred Moses and Suleiman A. Idi. Funding was from Chester Zoo, Nexen Inc., A.G. Leventis Foundation and Primate Conservation Inc. (PCI). 


\section{References}

Abwe EE, Morgan BJ (2008). The Ebo forest: four years of preliminary research and conservation of the Nigeria-Cameroon chimpanzee (Pan troglodytes vellerosus). Pan Africa News 15: 26.

Adanu J, Fowler A, Sommer V (2011). Hunters, fire, cattle. Conservation challenges in Eastern Nigeria, with special reference to chimpanzees. In Primates of Gashaka. Socioecology and Conservation in Nigeria's Biodiversity Hotspot (Sommer V, Ross C, eds.), pp 55-100. New York, Springer.

Anderson JR (1984). Ethology and ecology of sleep in monkeys and apes. Advances in the Study of Behavior 14: $165-230$.

Anderson JR (1998). Sleep, sleeping sites, and sleep-related activities: awakening to their significance. American Journal of Primatology 46: 63-75.

Anderson JR, Williamson EA, Carter J (1983). Chimpanzees of Sapo Forest, Liberia: density, nests, tools and meat-eating. Primates 24: 594-601.

Baldwin PJ (1979). The Natural History of the Chimpanzee (Pan troglodytes verus) at Mt. Assirik, Senegal. PhD Thesis, University of Stirling.

Baldwin PJ, Sabater Pi J, McGrew WC, Tutin CEG (1981). Comparison of nests made by different populations of chimpanzees (Pan troglodytes). Primates 22: 474-486.

Basabose AK, Yamagiwa J (2002). Factors affecting nesting site choice in chimpanzees at Tshibati, KahuziBiega National Park: influence of sympatric gorillas. International Journal of Primatology 23: 263282.

Beck J (2006). Chimpanzee Ecology at Ngel Nyaki Montane Forest, Eastern Nigeria. Project report submitted in partial fulfilment for the degree BSc (Hons) at the School of Biological Sciences, University of Canterbury, Christchurch.

Beck J, Chapman H (2008). A population estimate of the endangered chimpanzee Pan troglodytes vellerosus in a Nigerian montane forest: implications for conservation. Oryx 42: 448-451.

Boesch C, Boesch H (1989). Hunting behaviour of wild chimpanzees in the Tai National Park. American Journal of Physical Anthropology 78: 547-573.

Brownlow AR, Plumptre AJ, Reynolds V, Ward R (2001). Sources of variation in the nesting behavior of chimpanzees (Pan troglodytes schweinfurthii) in the Budongo Forest, Uganda. American Journal of Primatology 55: 45-55.

Carvalho JS (2015). Where to nest? Ecological determinants of chimpanzee nest abundance and distribution at the habitat and tree species scale. American Journal of Primatology 77: 186-199.

Chapman JD, Chapman HM (2001). Forests of Taraba and Adamawa State, Nigeria. An Ecological Account and Plant Species Checklist. Christchurch, University of Canterbury.

Chapman HM, Olson SM, Trumm D (2004). An assessment of changes in the montane forests of Taraba State, Nigeria, over the past 30 years. Oryx 38: 282-290.

De Bournonville D (1967). Contribution à l'étude du chimpanzé en République de Guinee. Bulletin de l'Institute Fondamental d'Afrique Noire Serie A 24: 1188-1269.

Dutton PE (2012). Chimpanzee (Pan troglodytes ellioti) Ecology in a Nigerian Montane Forest. PhD thesis, University of Canterbury, Christchurch.

Dutton P, Chapman H (2015). Dietary preferences of a submontane population of the rare NigerianCameroon chimpanzee (Pan troglodytes ellioti) in Ngel Nyaki Forest Reserve, Nigeria. American Journal of Primatology 77: 86-97.

Fowler A (2006). Behavioural Ecology of Chimpanzees (Pan troglodytes vellerosus) at Gashaka, Nigeria. $\mathrm{PhD}$ Thesis, University College London.

Fruth B (1995). Nests and Nest Groups in Wild Bonobos (Pan paniscus): Ecological and Behavioural Correlates. Aachen, Shaker.

Fruth B, Hohmann G (1994). Nests: living artefacts of recent apes? Current Anthropology 35: 310-311.

Fruth B, Hohmann G (1996). Nest building behaviour in the great apes: the great leap forward? In Great Ape Societies (McGrew AE, Marchant LF, Nishida T, eds.), pp 225-240. Cambridge, Cambridge University Press.

Furuichi T, Hashimoto C (2004). Botanical and topographical factors influencing nesting-site selection by chimpanzees in Kalinzu Forest, Uganda. International Journal of Primatology 25: 755-765.

Hakizimana D, Hambuckers A, Brotcorne F, Huynen MC (2015). Characterization of nest sites of chimpanzees (Pan troglodytes schweinfurthii) in Kibira National Park, Burundi. African Primates 10: $1-12$.

Hawthorne WD, Jongkind CCH (2006). Woody Plants of Western African Forests, a Guide to the Forest Trees, Shrubs and Lianes from Senegal to Ghana. Richmond, Kew Publishing.

Hayward MW, Henschel P, O’Brien J, Hofmeyr M, Balme G, Kerley GIH (2006). Prey preferences of the leopard (Panthera pardus). Journal of Zoology 270: 298-313.

Hernandez-Aguilar RA, Moore J, Stanford C (2013). Chimpanzee nesting patterns in savanna habitat: environmental influences and preferences. American Journal of Primatology 75: 979-994. 
Hicks TC (2010). A Chimpanzee Mega-Culture? Exploring Behavioral Continuity in Pan troglodytes schweinfurthii across northern DR Congo. PhD Dissertation, University of Amsterdam.

Hicks TC, Fouts RS, Fouts DH (2009). A survey of chimpanzees (Pan troglodytes troglodytes) and gorillas (Gorilla gorilla gorilla) in the selectively logged Ngotto Forest, Central African Republic. Journal of Applied Animal Welfare Science 12: 165-188.

Johnson AE, Knott CD, Pamungkas B, Pasaribu M, Marshall AJ (2005). A survey of the orangutan (Pongo pygmaeus wurmbii) population in and around Gunung Palung National Park, West Kalimantan, Indonesia based on nest counts. Biological Conservation 121: 495-507.

Kano T (1983). An ecological study of the pygmy chimpanzees (Pan paniscus) of Yalosidi, Republic of Zaire. International Journal of Primatology 4: 1-31.

Keay RWJ (1990). Trees of Nigeria. Oxford, Clarendon Press.

Knight A (2014). The Genetic Structure and Dispersal Patterns of the Nigeria-Cameroon Chimpanzee (Pan troglodytes ellioti). MSc Dissertation, University of Canterbury, Christchurch.

Koops K, McGrew WC, Vries HDE, Matsuzawa T (2012). Nest-building by chimpanzees (Pan troglodytes verus) at Seringbara, Nimba Mountains: antipredation, thermoregulation, and antivector hypotheses. International Journal of Primatology 33: 356-380.

Last C, Muh B (2013). Effects of human presence on chimpanzee nest location in the Lebialem-Moné Forest landscape, southwest region, Cameroon. Folia Primatologica 84: 51-63.

Matthews A, Matthews A (2004). Survey of gorillas (Gorilla gorilla gorilla) and chimpanzees (Pan troglodytes troglodytes) in Southwestern Cameroon. Primates 45: 15-24.

McGrew WC (1992). Chimpanzee Material Culture. Implications for Human Evolution. Cambridge, Cambridge University Press.

Plumptre A, Reynolds V (1997). Nesting behavior of chimpanzees: implications for censuses. International Journal of Primatology 18: 475-485.

R Development Core Team (2011). R: A Language and Environment for Statistical Computing. Vienna, R Foundation for Statistical Computing. http://www.R-project.org/.

Rayadin Y, Saitoh T (2009). Individual variation in nest size and nest site features of the Bornean orangutans (Pongo pygmaeus). American Journal of Primatology 71: 393-399.

Reynolds V (2005). The Chimpanzees of the Budongo Forest. Oxford, Oxford University Press.

Samson DR, Hunt KD (2014). Chimpanzees preferentially select sleeping platform construction tree species with biomechanical properties that yield stable, firm, but compliant nests. PLOS ONE 9: e95361.

Sept JM, King BJ, McGrew WC, Moore J, Paterson JD, Strier KB, Uehara S, Whiten A, Wrangham RW (1992). Was there no place like home? A new perspective on early hominid archaeological sites from the mapping of chimpanzee nests. Current Anthropology 33: 187-207.

Stewart FA (2011). The Evolution of Shelter: Ecology and Ethology of Chimpanzee Nest Building. PhD Dissertation, University of Cambridge.

Stewart FA, Piel AK, McGrew WC (2011). Living archaeology: artefacts of specific nest site fidelity in wild chimpanzees. Journal of Human Evolution 61: 388-395.

Stewart FA, Pruetz JD (2013). Do chimpanzee nests serve an anti-predatory function? American Journal of Primatology 75: 593-604.

Sun C, Kaplin BA, Kristensen KA, Munyaligogo V, Mvukiyjmwami J, Kajonda K, Moermond TC (1996). Tree phenology in a tropical montane forest of Rwanda. Biotropica 28: 668-681.

Tagg N, Willie J (2013). The influence of transect use by local people and reuse of transects for repeated surveys on nesting in western lowland gorillas (Gorilla gorilla gorilla) and central chimpanzees (Pan troglodytes troglodytes) in Southeast Cameroon. International Journal of Primatology 34: 554-570. 